\title{
Ixora (Rubiaceae) on the Philippines - crossroad or cradle?
}

\author{
Cecilia I. Banag ${ }^{1,2^{*}}$, Arnaud Mouly ${ }^{5}$, Grecebio Jonathan D. Alejandro ${ }^{1,2}$, Birgitta Bremer ${ }^{3}$, Ulrich Meve ${ }^{4}$, \\ Guido W. Grimm ${ }^{6}$ and Sigrid Liede-Schumann ${ }^{4}$ (i)
}

\begin{abstract}
Background: The Philippine archipelago is globally one of the most important model island systems for studying evolutionary processes. However, most plant species on this archipelago have not yet been studied in sufficient detail. The main aim of this study is to unravel the evolutionary history and biogeographic relationships of the Philippine members of the pantropical genus /xora.

Results: The complex plastid and nuclear divergence patterns in Philippine Ixora, documented using tree and network approaches, reveal a highly dynamic evolution in lxora, involving several phases of radiation and recolonization. Philippine Ixora comprises at least five lineages, of which one is most closely related to species from Wallacea, and the remaining four to species from Asia.

Conclusions: Our study highlights the importance of Philippine species for understanding phytogeographic patterns in the Indomalayan-Australasian eco-region. The overall genetic differentiation, as well as the incongruence between genealogies based on the biparentally inherited nucleome and the maternally inherited plastome in Ixora, reflect the complex tectonic history of the Philippine archipelago. The Ixora lineage related to Wallacean species supports the delimitation of different ecozones along Huxley's line, because it is absent from Palawan. The remaining four lineages are all allied with Asian taxa, reflecting several waves of colonization. Close relationships between some widespread Philippine species and locally adapted narrow endemics suggest that the widespread, genetically diverse species act as pools for the formation of new species in a process of ongoing speciation. Our results suggest that the species concepts of some of the more widespread taxa need to be revised.
\end{abstract}

Keywords: Huxley's line, incongruent genealogies, island biogeography, Ixora, molecular systematics, incomplete lineage sorting, Philippines, phylogeny, Rubiaceae, Wallace's line

\section{Background}

The importance of the Philippine archipelago for Southeast Asian biogeography was first recognized by Alfred Russel Wallace when he distinguished the Australian and Indian regions [1, 2]. He placed the Philippines in the Indian region, but considered them "in some respects of doubtful location". Later, he moved the Philippines into the Oriental region [3].

With almost 6000 endemic plant and more than 500 endemic vertebrate species, the Philippines constitutes

\footnotetext{
* Correspondence: cibanag@ust.edu.ph

${ }^{1}$ Department of Biological Sciences, College of Science, University of Santo

Tomas, España Boulevard, 1015 Manila, Philippines

${ }^{2}$ Research Center for the Natural and Applied Sciences, University of Santo

Tomas, España Boulevard, 1015 Manila, Philippines

Full list of author information is available at the end of the article
}

one of the 25 biodiversity hotspots for conservation priority and is among the leading ten hotspots regarding the number of endemics [4]. However, the complex geological history of the more than 7000 islands stretching over nearly $2000 \mathrm{~km}$ in North-South direction has made it difficult to understand the diversification of the rich plant and animal biodiversity in the country [5]. Nevertheless, biogeographers, population geneticists, conservation biologists, and phylogeneticists have been intrigued by the archipelago and its diverse endemic species, and have used it as a model system for addressing a variety of conceptual questions relating to evolutionary history. Consequently, the Philippine archipelago has become one of the globally important model island archipelagos for studying evolutionary processes of diversification [6]. Studies 
utilizing robust and well-sampled phylogenetic analyses as a basis for understanding the complex biogeographical histories of Philippine plants and animals have advanced in the last two decades; however, most of them are dedicated to animals [7-10]. Biogeographical studies including Philippine plants were conducted only for a few genera such as Cyrtandra J.R.Forst. \& G.Forst. (Gesneriaceae [11]), Rhododendron L. (Ericaceae [12]), Begonia L. (Begoniaceae [13, 14]), and Aglaia Lour. (Meliaceae [15]).

In the Philippines, Rubiaceae is the most diverse family, and $443(83 \%)$ of the 535 species found in the country are endemics [16]. Species diversity, phylogenetic and biogeographical relationships of Philippine Rubiaceae have received renewed interest in recent years. Greeniopsis Merr. (Ixoroideae: Aleisanthieae) has been identified as an endemic Philippine genus with its closest relatives (Aleisanthia Ridl. and Aleisanthiopsis Tange) in Southeast Asia [17]. Likewise, the endemic Philippine genus Antherostele Bremek. (Rubioideae: Urophylleae) is most closely related to a set of Southeast Asian genera (Maschalocorymbus Bremek., Pleiocarpidia K.Schum., Praravinia Korth., Pravinaria Bremek., Urophyllum Jack ex Wall. [18]). In contrast, the endemic Philippine genus Villaria Rolfe (Ixoroideae: Octotropideae) forms a well-supported clade with the Southeast Asian genus Hypobathrum Blume and the West African genus Pouchetia A.Rich. [19].

None of these endemic genera comprise more than six species, and little is known about species diversity, phylogenetic and biogeographical relationships of the Philippine representatives of other, larger Rubiaceae genera. The pantropical genus Ixora L. (Ixoreae [20]) is the third largest genus in the family Rubiaceae, with approximately 530 species [16], most of them shrubs or small trees in the understorey of tropical forests. Approximately 280, (possibly up to 300 ) species occur in tropical Asia [21], with 44 species in India [22], 38 in Thailand [23] and 66 species on Borneo alone [24]. In contrast, only 37 species are known from continental Africa, about 40 species from Madagascar and 35 species from tropical America [21, 25]. Ixora is one of the largest Rubiaceae genera on the Philippines, and one of the best recognizable: Morphologically, it is characterized by a combination of articulate petioles, terminal trichotomously branching inflorescences, narrowly tubular 4-merous flowers, contorted aestivation, a single ovule per locule, and drupaceous fruits and seeds with a large adaxial excavation [21]. However, identification at species level is much more difficult [21]. While several taxonomic treatments of Ixora are available for specific geographical regions such as Africa [21], Madagascar [25], the Marquesas Islands [26], and Australia [27], a revision of the continental Asian taxa is lacking.
Therefore, species delimitation is not yet fully understood, and the actual number of species is still unknown [28].

Previous phylogenetic studies have clarified the tribal placement and circumscription of the genus [20, 29-31]. Mouly et al. [31] resolved Ixora species into two large lineages, an Asian-Pacific lineage (43 species covered) and an Afro-Neotropical lineage (34 species covered). Tosh et al. [32] recently investigated the evolutionary history of Afro-Madagascan Ixora and recovered two separate lineages of Madagascan taxa. They [32] estimated an Ixoreae crown age of 17 million years ago (Ma) and dated the onset of divergence between the Asian-Pacific clade and the remainder of the genus as $15 \mathrm{Ma}$, indicating a mid-Miocene origin (cf. [33]) for the lineages, in agreement with the results of Mouly [28]. No samples from the Philippines have been included in any study so far.

In the Philippines, the genus Ixora provides an exemplary case, with a particularly high number of endemic species known from the country (30 out of 41 species $[34,35])$. The only available prior account was an enumeration by Merrill [36], more than 85 years old and outdated (e.g. [20, 37-39]). Preliminary investigation of type material and available herbarium specimens showed that species of Ixora in the Philippines are distinguished based on subtle differences of the inflorescences and morphoclines rather than discrete characters, e.g. length ratio of the corolla tube vs. corolla lobe, and the pubescence of the inflorescence [35]. This corresponds to De Block's [21] observations regarding their African congeners.

In this study, we include for the first time a wide range of Philippine Ixora species in a phylogenetic analysis using sequence data from two chloroplast regions, the rps16 intron and the trnT-F region including the trn $\mathrm{T}$ $\operatorname{trn} \mathrm{L}$ and $\operatorname{trn} \mathrm{L}-\operatorname{trn} \mathrm{F}$ intergenic spacers and the $\operatorname{trn} \mathrm{L}$ intron, and the $5^{\prime}$ external transcribed spacer (ETS) and internal transcribed spacers (ITS1, ITS2) of the nuclearencoded 35S rDNA cistron. We interpret our results in the light of the hitherto known patterns of faunal and floral migrations and evolution in the Philippines. We address the following questions. (1) Are the Philippine Ixora species monophyletic? (2) Are phylogenies derived from chloroplast and nuclear DNA congruent? (3) Which species or groups of species are the closest relatives of the Philippine Ixora species? (4) Does the phylogenetic pattern of Philippine Ixora have wider implications on the biogeographic history of the Philippines?

\section{Results}

Outgroup sampling and ingroup sequence characteristics One of the non-coding gene regions used here, the nuclear-encoded ITS1, cannot be aligned across all 
Ixoroideae, and alignment of the most divergent and length-polymorphic plastid region, the $\operatorname{trn} \mathrm{T}-\operatorname{trn} \mathrm{L}$ intergenic spacer, is difficult in some parts. Also, the other two nuclear spacers, the ITS2 and the ETS, include sequence portions that will lead to ambiguous alignments when incorporating all Ixoroideae data. Nonetheless, we could infer four guide trees based on the harvested data (ETS, ITS excluding non-alignable regions, rps16 intron, entire trnT-F region), which confirmed that our outgroup selection includes the closest relatives of Ixora with best-possible data coverage on the gene regions used here (see Additional file 1).

The 151 new sequences generated in this study were combined with sequences previously generated and used by Mouly et al. [30, 31] and Tosh et al. [32] resulting in a total of 264 sequences of 78 Ixora samples, representing approximately 60 Ixora species. Levels of genetic variation between species were generally low for all investigated regions. The total number of parsimony informative characters (PICs) ranged from 40 in rps 16 to 122 in ETS for the ingroup; the number of distinct alignment patterns (DAPs) ranged from 209 in rps16 to 450 in trnT-F. In the concatenated cpDNA dataset, 265 characters $(10 \%)$ were variable, with 360 characters (32.4\%) variable in the nuclear dataset. The characteristics of the individual chloroplast and nuclear regions are listed in Table 1.

\section{Incongruence and congruence between nuclear and plastid genealogies}

Phylogenetic analyses of individual gene regions generate largely unresolved and poorly supported phylogenetic trees (data not shown). Concatenation of the nuclear data and the plastid gene regions respectively leads to better resolved phylogenetic trees (Fig. 1) and limits the number of scenarios of potential phylogenetic relationships between species and clades (Figs. 2 and 3).

Two large, mutually monophyletic lineages, an Asian-Pacific clade (I) and an Asian-Afro-Neotropical clade (clades II-IV), are inferred based on the nuclear dataset (Figs. 1a and 2). Based on the plastid data, three main clades emerge: a Philippine clade (A), a mixed Asian-Pacific clade (B), and a clade including the African and New World species (clade C; Figs. 1b and 3). The nuclear tree suggests a split between the Indian-Mascarene species and the remainder of the African-New World clade. A nuclear clade III corresponds to the plastid clade C. This is the bestsupported (via bootstrapping, BS) and most probable (regarding Bayesian inferred posterior probabilities, PP) clade (Figs. 1 and 2). In both phylogenies, the American taxa I. aluminicola and I. ferrea are nested in the African subtree(s). Taking the nuclear and plastid inferences together, four or five main lineages can be defined based on the exclusive combination of nuclear and plastid signatures: Ia/A (red in Figs. 1, 2 and 3$), \mathrm{Ib} / \mathrm{B} 1$ (orange), II+IV/B (green and purple), and III/C (blue). The nuclear clade Ia corresponds exactly to the plastid clade A. Based on nuclear data, this clade (Ia) is sister to a clade of Asian-Pacific species (Ib) with B-type plastids (clade B1 in Fig. 1). Based on plastid data, this clade (A) is sister to the remaining taxa, reflecting a deep incongruence. Although different in their nuclear signatures, the members of the nuclear clades II and IV share the same plastid. Consistently, the plastid haplotypes of members of clade II appear to be generally more derived (to different extents) and include unique ribo-/haplotype combinations (II/B2 and II/B3; see below) as reflected by their placement in the plastid tree and the support of critical branches (Figs. 1, 2 and 3).

Both the nuclear and chloroplast maximum likelihood (ML) trees (Fig. 1a and b; see Additional file 2 for the corresponding trees including cultivars) placed the 35 samples (24 species) of Philippine Ixora in five distinct subtrees. The positions and support of the five corresponding clades, however, differ between the two datasets. Lineage Ia/A is exclusively Philippine. The remaining four clades comprising Philippine species mixed with Southeast Asian species are part of lineage(s) II+IV/B. The structure of the nuclear clade II reflects two radiations with Philippine species. While the

Table 1 Information for phylogenetic analyses (rps16, trnT-F, ITS and ETS, ingroup only)

\begin{tabular}{|c|c|c|c|c|}
\hline & rps16 & $\operatorname{trnT}-\mathrm{F}$ & ITS & ETS \\
\hline No. of sequences investigated & 74 & 75 & 73 & 65 \\
\hline No. of new sequences & 39 & 40 & 40 & 32 \\
\hline Range of sequence length (bp) & $593-876$ & $767-1744$ & $552-791$ & $282-436$ \\
\hline Length of aligned matrices (bp) & 847 & 1798 & 676 & 436 \\
\hline Proportion of gaps and undetermined characters & $14.4 \%$ & $16.3 \%$ & $6.3 \%$ & $5.5 \%$ \\
\hline Number of variable characters & $96(11.3 \%)$ & $169(9.4 \%)$ & 175 (25.9\%) & $18542.4 \%)$ \\
\hline Number of PIC & $40(4.7 \%)$ & $70(3.9 \%)$ & $106(15.7 \%)$ & $122(28.0 \%)$ \\
\hline Number of DAP & 209 & 450 & 248 & 260 \\
\hline
\end{tabular}

Abbreviations: DAP distinct alignment patterns, PIC parsimony-informative characters 


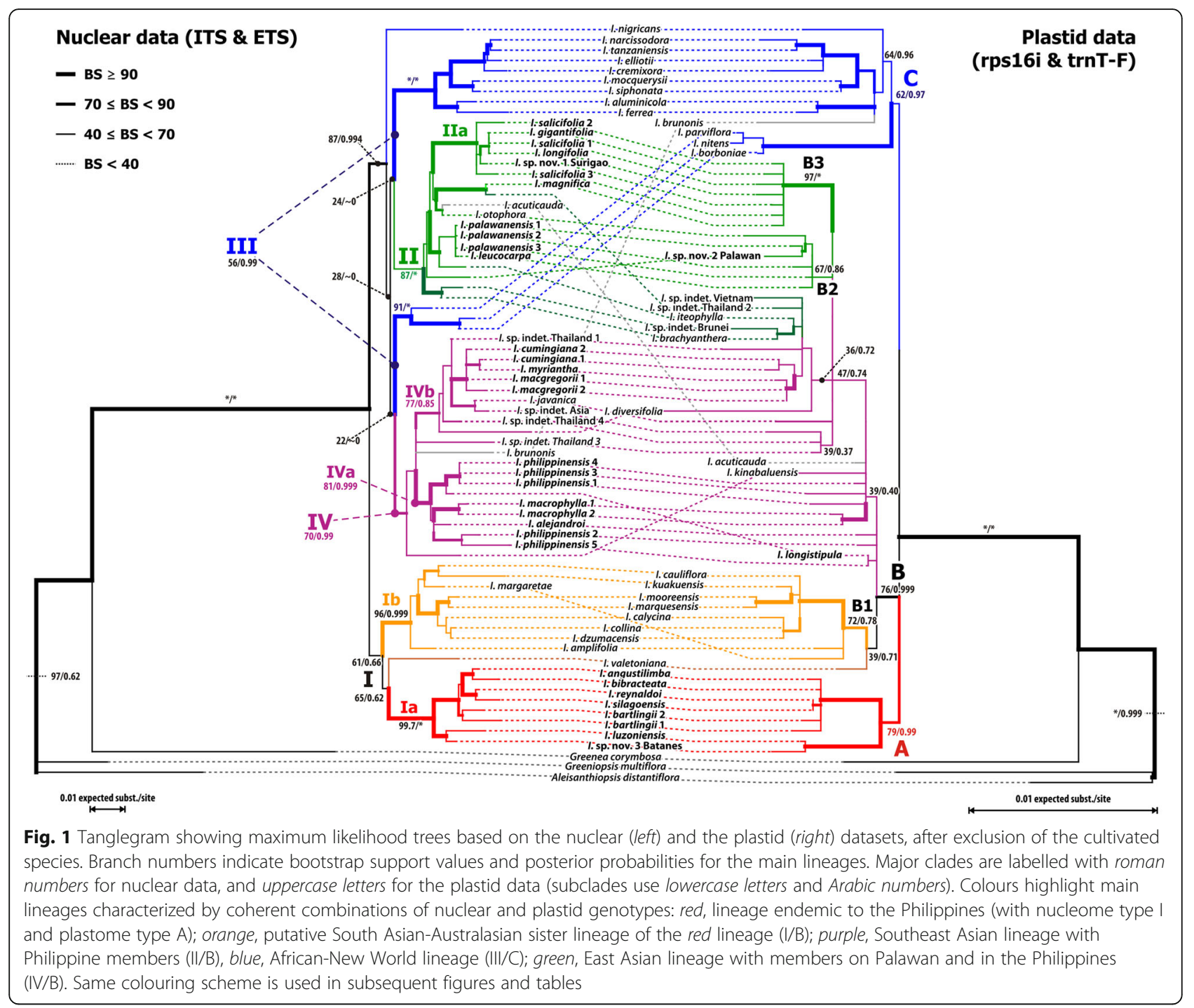

exclusively Philippine subclade IIa matches exactly the chloroplast clade B3, composition and arrangement of the I. palawanensis subclade (clade B2) differs between the two datasets. Using the nuclear data the Malayan $I$. iteophylla is included in this clade but I. otophora and I. sp. nov. 2 "Palawan" are excluded. A similar situation is found in nuclear clade IV; one subclade (IVa) is exclusively Philippine, while the other (subclade IVb) is comprised of both Philippine and several Southeast Asian species. In the chloroplast tree, these two radiations do not correspond, and the involved species are largely unresolved.

Multiple accessions of the same species are placed in the same subclades (I. palawanensis, I. salicifolia, I. macgregorii, I. cumingiana); but only I. bartlingii and I. macrophylla are resolved as actual sisters, irrespective of the data used (nuclear or plastid). The highest variability is encountered in the five accessions of $I$. philippinensis which fall into two groups with (to some extent) different plastid and nuclear signatures.

\section{Signal ambiguity in nuclear and plastid data sets}

Detailed inspection of split patterns in the bootstrap samples (Figs. 2 and 3; datasets excluding cultivars) demonstrate that the nuclear types are generally more distinct than the plastid types of the same specimens; this is illustrated in the more tree-like general structure of the nuclear-based bootstrap network. Signal ambiguity in the nuclear data relates to the initial radiation within the core group Ixora and the initial diversification of clade III. The plastid signal is not sufficiently clear either to resolve several backbone relationships. Most importantly, the signal from many Philippine taxa of clade B commonly is ambiguous. Other taxa (or pairs of taxa) inflicting topological ambiguity at deeper nodes in the 


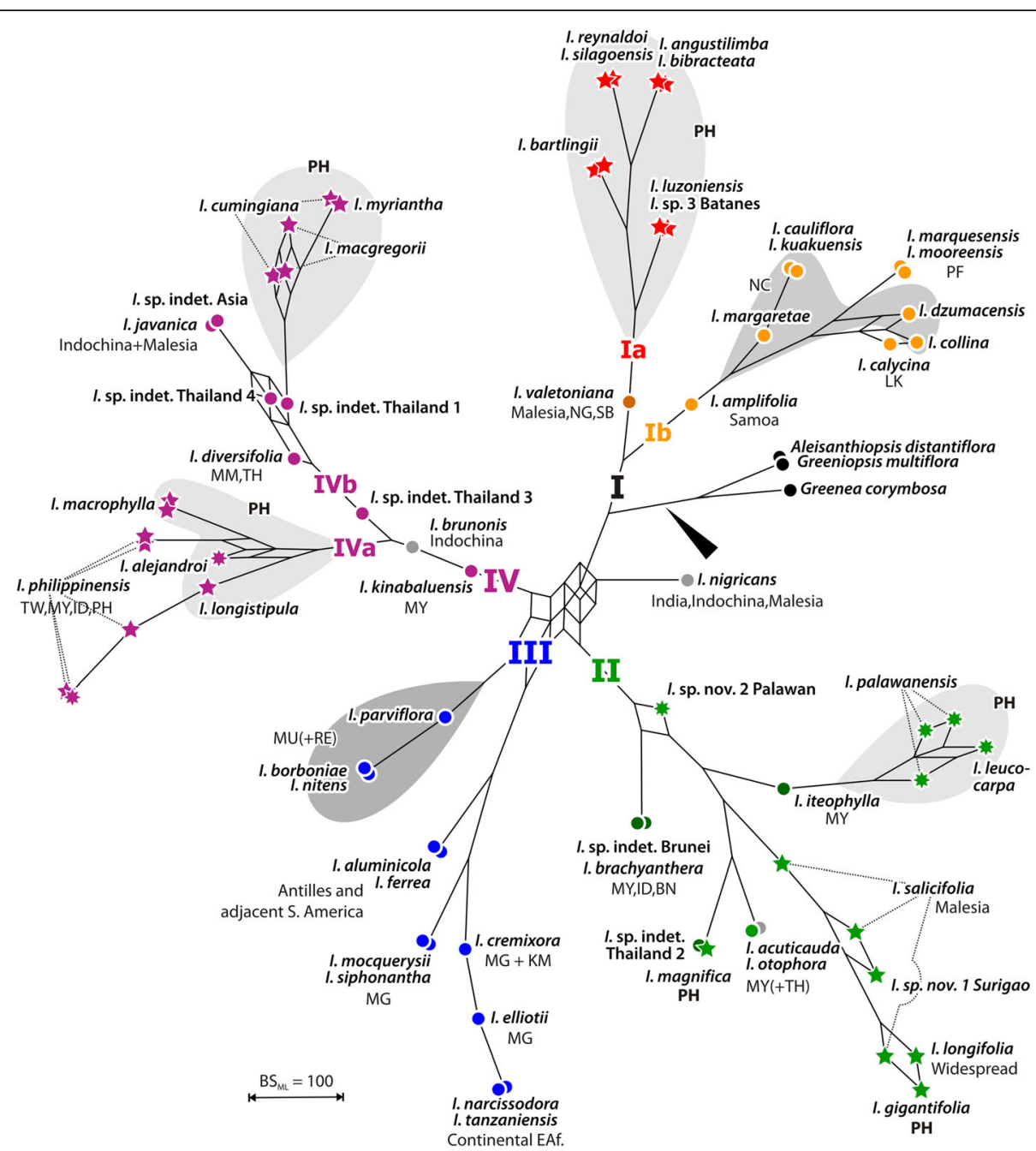

Fig. 2 Bootstrap support network, nuclear data. Ambiguous signal in the nuclear data (excluding cultivars) visualized using bipartition (bootstrap support) networks [80, 82], a special from of consensus networks in which the edge lengths are proportional to the frequency of the corresponding phylogenetic split in the bootstrap (BS) replicate sample The bootstrap support network is based on 400 BS replicate trees inferred from the nuclear data.. Members of major lineages (see Fig. 1) coloured accordingly, outgroups in black. Circles, non-Philippine individuals; 7-pointed stars, Palawan samples; 5-pointed stars, other Philippine samples. (Corresponding posterior probability networks can be found in Additional file 2)

Ixora core group plastome are I. diversifolia, I. javanica, I. acuticauda, I. kinabaluensis, and I. valetoniana.

Individual taxa of unclear affinity are: 1) I. nigricans from India, with somewhat inconclusive nuclear signals but an African-American -type chloroplast; 2) I. brunonis from Thailand with Southeast Asian nuclear signals but an African-American type chloroplast; and 3) I. acuticauda from Borneo with incongruent Asian nuclear and chloroplast types.

Further topological ambiguity arises from to the cultivated taxa which occupy markedly different positions in the nuclear- and plastid-based inferences (Additional file 2). The cultivars Ixora finlaysoniana, I. pavetta, I. casei, and I. chinensis are nested in the Asian (including Philippines) nuclear-based clade IV; but their plastid affinity lies with the New-World African clade C.
Similarly, I. brunonis from Thailand is the poorly supported sister of I. casei and I. chinensis in the nuclear tree (all members of clade IV), while it is the wellsupported sister of I. finlaysoniana in the cpDNA tree (subclade of clade C). The accession of I. finlaysoniana cultivated in the Philippines always formed a strongly supported clade with an accession cultivated in Tanzania. The last cultivar, Ixora coccinea, retains its association with a second clade of Asian (including Philippine) species in both trees (clades II, clade B), but changes position inside this clade.

\section{Biogeographic patterns in Ixora with special reference to Philippine taxa}

In the Philippines, distantly related nuclear lineages occur sympatrically (Fig. 4a, stars), indicating that 


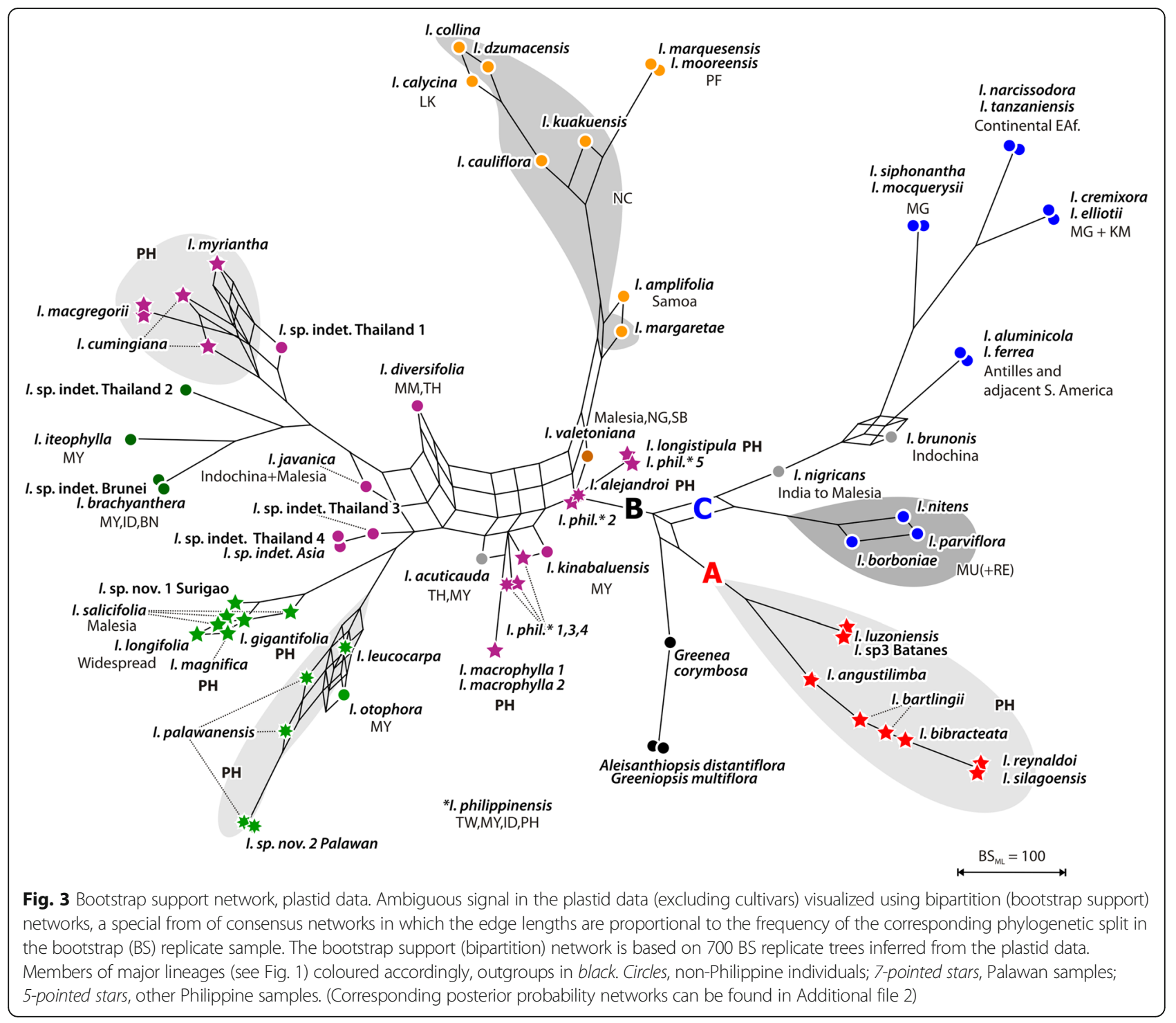

natural populations of the main lineages are genetically isolated. Plastids in Ixora are geographically sorted. With a few exceptions, each nuclear lineage (Ia, Ib, II, III, and IV) carries one sort of plastid haplotype (A, B or C) (Figs. 4 and 5). The outgroup-inferred root suggests an initial split in Ixora between a lineage that today occurs from the Pacific Islands to the Philippines (except for Palawan) with an outlier in Sri Lanka (yellow in Fig. 4a), and the rest of the genus (light blue). Plastid variation indicates substantial genetic drift between African (lineage III/C; blue signatures in Fig. 4b) and South Asian-Indomalayan members (green and purple signatures in Fig. $4 \mathrm{~b}$ ) of the genus in general, and the two Pacific-Philippine potential sister lineages $\mathrm{Ia} / \mathrm{A}$ and $\mathrm{Ib} / \mathrm{B} 1$ (red and orange signatures, respectively). Plastid signatures indicate that the now mostly Pacific lineage $\mathrm{Ib} / \mathrm{B} 1$ (orange) and the South AsianIndomalayan group (lineage[s] II + IV/B; green, purple) within Ixora evolved within or near to the same geographically restricted area(s) (grey plastid clade, Fig. 4b). At the time of this divergence, both the African (blue) and the exclusively Philippine (red) Ixora were geographically isolated from the main bulk of South Asian-Indomalayan Ixora (Fig. 4b).

\section{Discussion}

\section{Relationships of the Philippine Ixora species}

Well-supported incongruence between the nuclear and the plastid datasets prevents the analysis of a combined dataset $([40,41]$, and references therein). Therefore, the two different genealogies were explored separately.

Our main nuclear clades, the Asian-Pacific clade (I) and the Asian-Afro-Neotropical clade (II-IV), correspond to those of Mouly et al. [31], who also found an Afro-Neotropical and a Pacific clade. However, while Mouly et al. [31] inferred a poorly supported monophyletic Asian clade, our greatly increased sampling of 

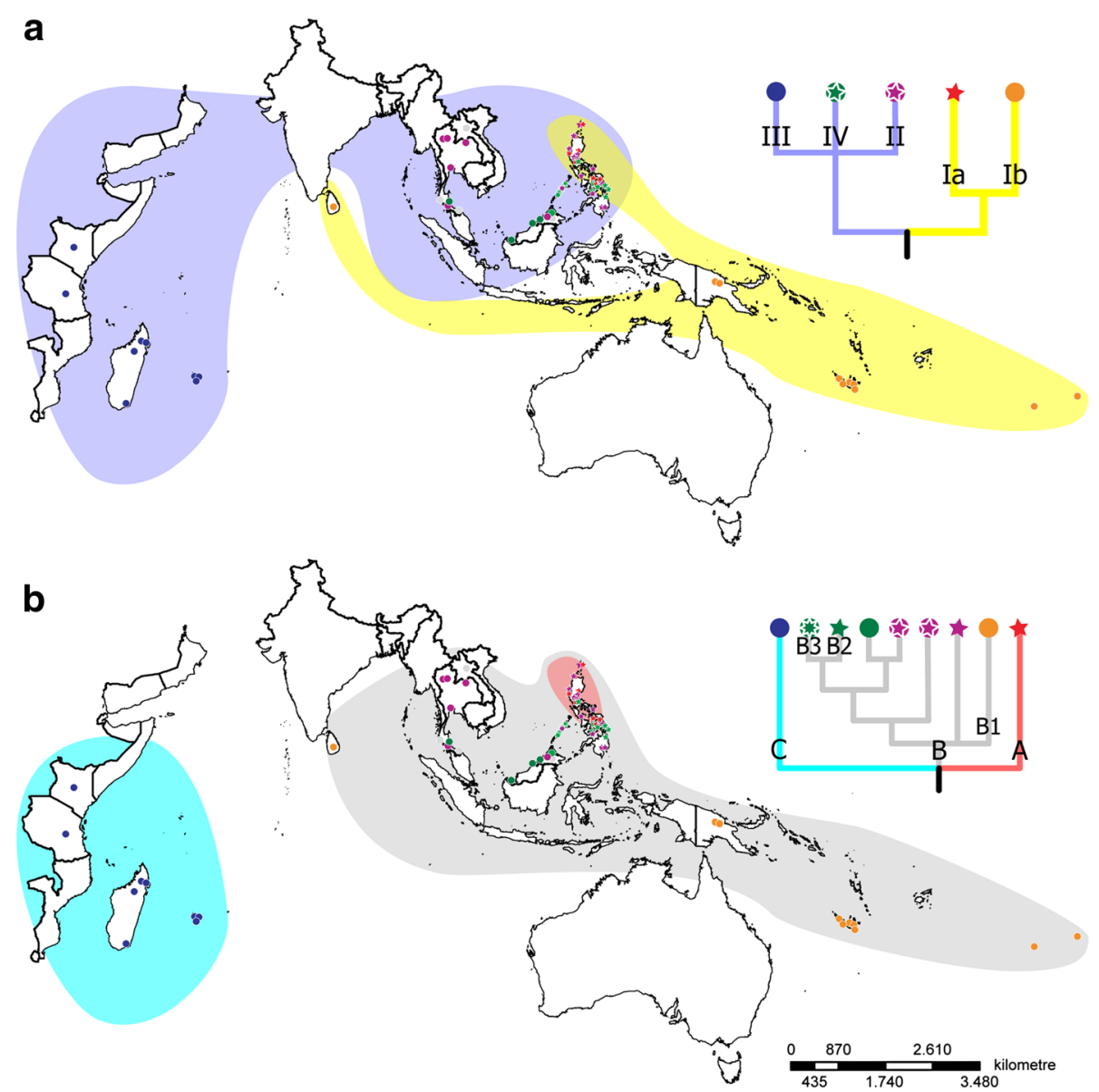

Fig. 4 Overview map including all analysed samples. Geographic distribution of nuclear-inferred (a) and plastid-inferred (b) lineages within sampled Ixora. Phylogenetic relationships of distinguished nuclear and plastid lineages are depicted as schematic cladograms, root as defined by outgroups (branches with non-high support collapsed to polytomies). Members of major lineages (see Fig. 1) coloured accordingly, grey: not genotyped individuals. Circles, non-Philippine individuals; 7-pointed stars, Palawan samples; 5-pointed stars, other Philippine samples

Asian, and in particular Philippine taxa, shows that Asian (including Philippine) species occur in both major clades in Ixora.

The species from the Philippines are represented in five different lineages, corresponding to three major ribo -/haplotypes in the nuclear and the chloroplast dataset. Two of these ribo-/haplotypes are shared with mainland Southeast Asian species, while the third one is a rather distant relative (putative sister lineage) of an AsianPacific lineage. Thus, the phytogeographical relationships of the Ixora species found in the Philippines are fully decoupled.

Lineage Ia/A comprises a strongly supported, genetically isolated group of endemic Philippine Ixora species that possibly share a common, potentially widespread (see plastid signatures) ancestor with a lineage (Ib/B1) composed of species from the wider Pacific area, which also includes I. calycina from Sri Lanka and southern India. Ixora angustilimba and I. bibracteata are strongly supported sister species, both characterized by solitary
(Fig. 6b) or at the most, three, flowers in an inflorescence supported by bracts $[42,43]$. Sister to these two species are two recently described species, $I$. reynaldoi and $I$. silagoensis $[44,45]$. Both species are characterized by subsessile leaves, sessile or shortly pedunculate, erect and lax inflorescences (Fig. 6c). Nested in this group are the two samples of $I$. bartlingii characterized by longpedunculate, pendulous inflorescences bearing numerous flowers (Fig. 6a). The sister clade to this group contains I. luzonensis and I. sp. indet. 3 "Batanes", which differ from their relatives by their shortly pedunculate and lax inflorescences.

The nuclear clade II, one of the two lineages with exclusively B-type plastids, contains two well-supported subclades, one of them exclusively consisting of Philippine (without Palawan) species (subclade IIa) with derived plastids (plastid clade B3; Figs. 1, 3 and 5). The 'plesiomorphic' plastids found in other members of the same lineage including all samples from Palawan, cause the ambiguous, but weak signals along the proximal part 


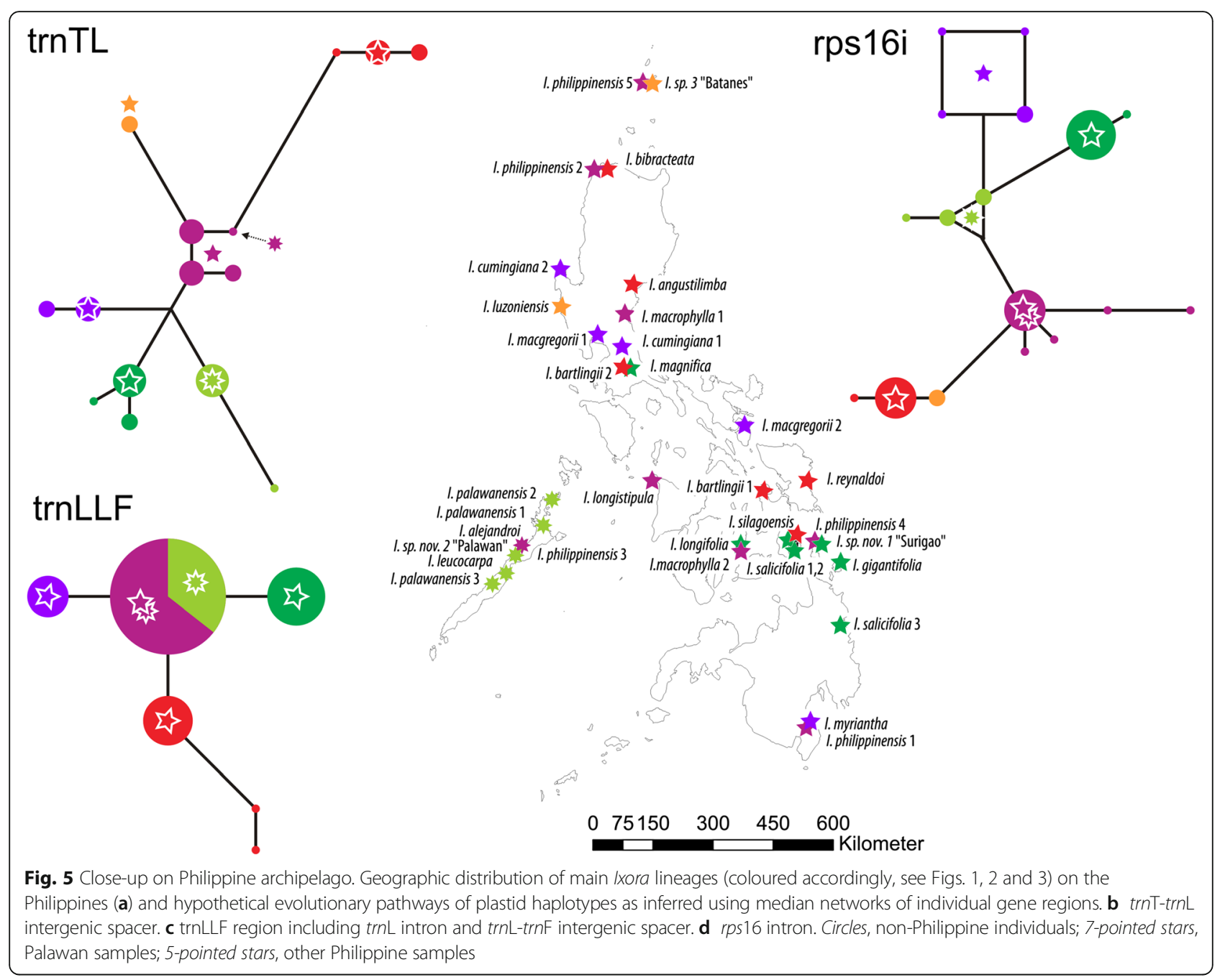

of the B-type subtree, characterizing, to various degrees, all members of clades II and IV (Figs. 1 and 3). The Palawan clade B2 (subclade of clade II in the nuclear tree) comprises I. palawanensis and I. leucocarpa (Figs. 1, 2 and 3). Ixora sp. nov. 2 "Palawan" is sister to these species included in clade B2, but outside the I. palawanensis-I. leucocarpa subclade in the nuclear tree, where it is sister to the Malayan I. iteophylla. Though sharing similar habitats, forested ravines or humid forest, the species of the Palawan clade differ in their flower colour (I. palawanensis, salmon-red (Fig. 5j); I. leucocarpa, white; Ixora sp. nov. 2 "Palawan", orange).

The three accessions of I. salicifolia are all part of clade B3 in the plastid tree and of IIa in the nuclear tree, but are not resolved as discrete clades (Fig. 1). Ixora longifolia and I. gigantifolia group with I. salicifolia 1 in the nuclear tree, while I. salicifolia 2 and I. salicifolia 3 remain unresolved. All species in this group possess derived, similar or identical, haplotypes of lineage B (Fig. 5, Additional file 3) and share morphological traits: pedunculate, erect and compact inflorescences and long-pedicellate flowers (Fig. 6k). Ixora magnifica, another Philippine endemic with showy bright red flowers, is resolved with high support as sister to an unidentified accession from Thailand in the nuclear tree, while sharing the characteristic B3 haplotype.

Within the third Ixora lineage (IV/B) found in the Philippine archipelago, the differentiation patterns are less clear. Of the widespread species I. philippinensis, two samples collected in the northern part of the Philippines (I. philippinensis 2 and 5 from Ilocos Norte and Batanes) are sister of the widespread, but monophyletic I. macrophylla (Aurora and Cebu) and I. alejandroi (Palawan), and are separated from the three samples collected in the southern part of the country (Palawan, Surigao and Davao). In the nuclear tree, the latter are contained within the sister clade of I. longistipula (Panay), a species characterized by pendulous inflorescences in which the flowers form a simple, dense head (Fig. 6g). Tosh et al. [32] observed a similar pattern for $I$. 


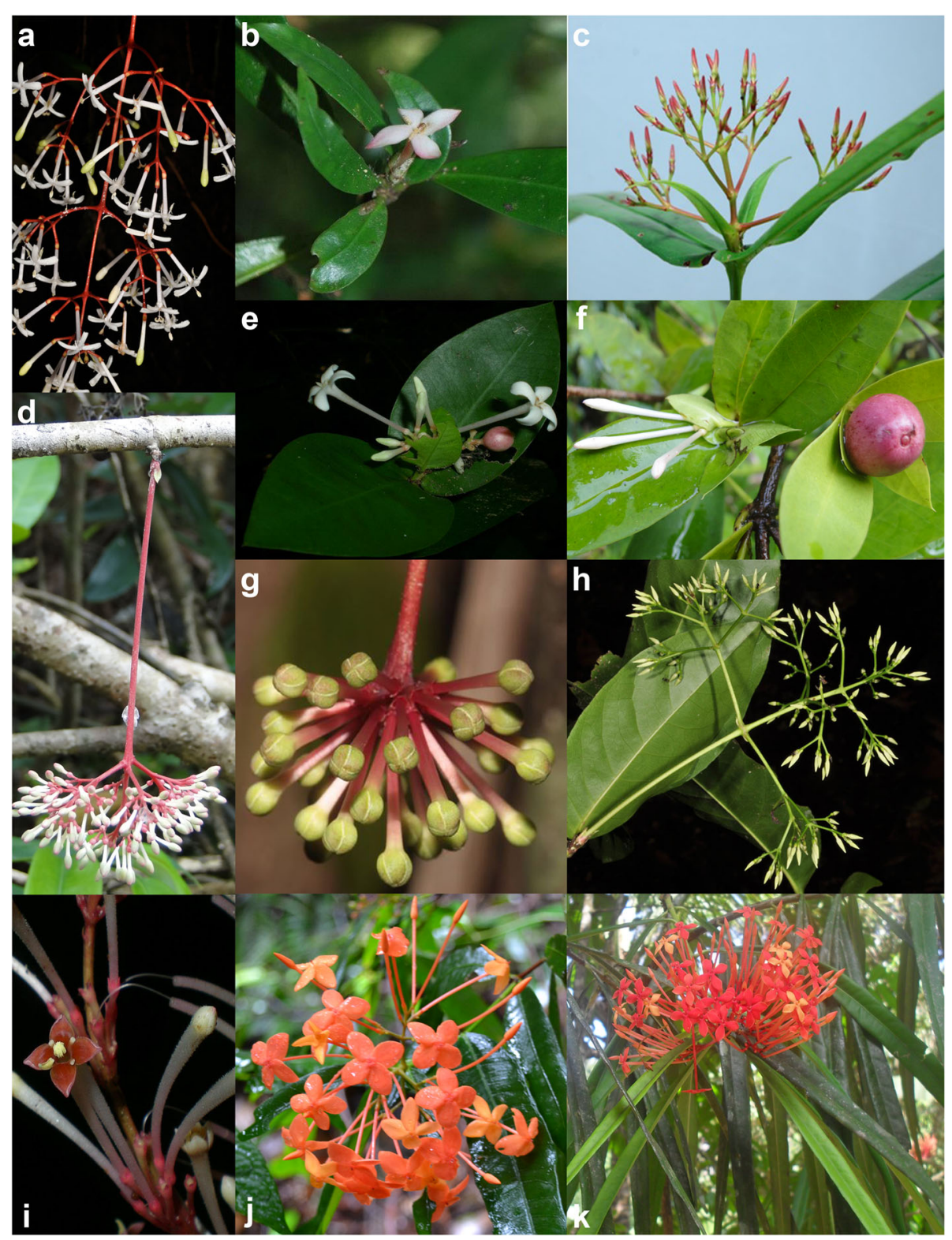

Fig. 6 Examples of species of the five subclades of the Philippine Ixora. a Ixora bartlingii Elmer (Pelser et al., 2011 [92]); b Ixora angustilimba Merr. (Banag 11-032, USTH); c Ixora silagoensis Manalastas, Banag \& Alejandro (Banag 12-037, USTH); d Ixora macrophylla Bartl. ex DC. (Banag 11-053, USTH); e Ixora philippinensis Merr. (Tandang DT548, PNH); f Ixora philippinensis Merr. (Alejandro 11-102, USTH); g Ixora longistipula Merr. (Pelser et al., 2011 [92]); h Ixora cumingiana Vid. (Pelser et al., 2011); i Ixora alejandroi Banag \& Tandang (Tandang MH1707, PNH); j Ixora palawanenis Merr. (Medecillo MPM 471, USTH); k Ixora salicifolia DC. (Banag SU002, USTH). — Credits: P. Pelser (A, H); G. Alejandro (B, D, F); J. Dela Bajan (C); D. Tandang (E, l); R. Bustamante (G); C. Banag (K)

mangabensis, in which the populations from northern and southern Madagascar did not form a natural group and exhibited small morphological differences. In I. philippinensis, the material collected from the north has longer peduncles and many flowers per inflorescence (Fig. 6e) compared to the (sub-)sessile to shortly pedunculate inflorescences with at most ten flowers per cyme in materials collected from the south (Fig. 6f). Reevaluation of the taxonomy of $I$. philippinensis is required in view of the genetic differentiation and morphological variation observed between these populations currently united in this species. The Palawan endemic $I$. alejandroi did not group with other species of Palawan (II/B2; Fig. 1). Ixora alejandroi (Fig. 6i) is characterized by an elongated cyme with congested secondary axes, reddish brown corolla and stigmatic lobes shortly cleft in the middle; characters which are not known from any other Philippine species [45]. Except for a pubescent 
inflorescence and non-articulate branching of the inflorescence axes, I. alejandroi shares no morphological characters with $I$. macrophylla and I. philippinensis. Its plastids are plesiomorphic within the IV/B lineage (cf. Fig. 3, Additional file 3, and median-joining networks in the online supplementary archive).

Subclade IVb (Fig. 1) comprises the two samples of $I$. cumingiana from Luzon, I. myriantha (Davao) and two sterile accessions attributed to I. macgregorii (Sorsogon). These species share white flowers and lax inflorescences (Fig. 6h), which become more compressed towards the south.

In our study, some species thought to be closely related based on morphology were placed in different subtrees (clades). This is the case with I. macrophylla, I. bartlingii, and I. longistipula, which are often misidentified in herbarium collections due to their longpedunculate, pendulous inflorescences with white corollas and overlapping shape of the leaves. However, other morphological characters support their separation in the phylogenetic tree, particularly the articulate, terminal inflorescences of I. bartlingii and I. longistipula as opposed to the non-articulate, cauli- or ramiflorous inflorescences of I. macrophylla (Fig. 6d) as well as the sessile to capitate flowers of I. longistipula (Fig. 6g) as opposed to the pedicellate flowers of I. bartlingii and I. macrophylla (Fig. 6a and d).

It is interesting to note that the most widespread and variable Philippine species (e.g., I. philippinensis, I. salicifolia) are found in different groups, associated genetically with morphologically related species of narrower distribution. This suggests that these widespread, genetically diverse species might act as pools for the diversification of locally adapted new species in a process of ongoing speciation, as recently shown for I. margaretae in New Caledonia [46].

While our investigation provides unequivocal evidence for the polyphyly of the Philippine Ixora, the relationships of several species to related species from the Asian mainland remain to be studied in more detail, because the plastid tree (in particular) is not yet well resolved inside clade B. Lineage sorting in this complex group appears yet to be incomplete (Fig. 1). Moreover, our present results indicate that several species from Asia display unusual combinations of nuclear and plastid ribo -/haplotypes (I. acuticauda and I. brunonis from Thailand, I. nigricans from India; Figs. 1 and 2, Additional file 3) that could be indicative of recent or ancient reticulation between major lineages (introgression, hybridization, as already discussed in Mouly et al. [31]). However, an enlarged sampling of Malesian and Indian taxa and an increased number of loci will most likely refine our results for clade B. Ultimately, the combination of additional, more variable plastid markers and the nuclear markers used here should be able to discriminate further between reticulation and incomplete lineage sorting; the latter appears to be a minor issue in Ixora, but it may account for the pattern seen in Southeast Asian/Malesian species of lineage(s) II+IV/B. Reticulation, possibly caused by hybridization [31, 32, 47], is indicated in particular for the cultivated species in our nr- and cpDNA trees (Additional file 2) by their conflicting, relatively terminal positions.

\section{Endemism}

Twenty-one of the 24 Philippine species included in this phylogenetic study are endemic to the Philippines. The three non-endemic species are I. longifolia, I. philippinensis, and I. salicifolia. While lineages Ia/A and II/B2 comprise only species endemic to the Philippines, lineages IVa/B, IVb/B and II/B3 contain both species endemic to the Philippines and species also reported from a wider Asian range. In clade IVa, both I. macrophylla and I. philippinensis are reported from all major Philippine islands including Palawan, and I. philippinensis is supposed to also occur in other areas of Malesia, and as far as Taiwan. However, in our analysis, the multiple accessions of I. philippinensis occur in two relatively distinct, well-supported nuclear subclades (Fig. 1, Additional file 2). This raises the question whether I. philippinensis represents a single species. The type specimen of I. philippinensis comes from Bataan, a peninsula in central Luzon, neither included in the area of the northern nor of the southern samples. Therefore, it is not yet clear whether one of these two lineages constitutes I. philippinensis in the sense of the protologue or whether the central Philippines might be home to a another, the typical, sublineage. More samples, including material from outside the Philippines presently included in I. philippinensis, need to be studied with combined morphological and molecular data to assess species boundaries within lineage $\mathrm{IVa} / \mathrm{B}$.

Lineage II/B3 comprises species centred in Mindanao and the Visayas, except for I. salicifolia which is widely distributed in the Philippines and also found in Borneo and Java. In this case, the present species concept may still apply, as the interspecies relationships in this subclade are unresolved. All members of lineage II/B3 apparently share a recent common geographic origin (note the length of the subtree roots in Fig. 1). Should further studies identify $I$. salicifolia in Malesia as an emigrant from the Philippines, it would underpin the key role of Mindanao as stepping stone for Ixora dispersal in the region [48]. Our sample identified as I. longifolia comes from Cebu and thus represents a typical member of the exclusively Philippine lineage II/B3. In the Philippines, this species is reported from southern Luzon, the 
Visayas, Mindanao and Palawan [35]. However, the type of I. longifolia was collected on the island of Honimoa (Moluccas, Indonesia) [49]. Further reports come from Borneo, Sumatra, and Amboina [35]. This may be an example for a species colonizing from the Philippines. However, because its area includes the Sunda Shelf (Borneo) and both western and eastern Wallacea (sensu [50]) and is thus extremely large for an Ixora species, detailed combined molecular and morphological analyses are necessary to establish whether the current concept of this species is valid.

\section{Biogeography}

The signal from nuclear and plastid data is far too complex to allow for application of currently available methods of biogeographic inference. All current methods need a fully-, or at least well-resolved, ultrametric phylogenetic tree as input. Computation of such trees for the nuclear and plastid data, which would provide the necessary discriminating topology to obtain meaningful ancestral area reconstructions, is not feasible based on the available data. Signal strength is a limiting factor in the nuclear, and to aneven greater extent, the plastid, data. Deep incongruences prevent concatenating both data sets. In addition to primary nuclear-plastid incongruence, the genetic complexity in Ixora indicates phases of secondary reticulation (I. brunonis, possibly $I$. acuticauda) and incomplete lineage sorting (situation in lineages II+IV/B). These two evolutionary phenomena, not uncommon at the intra-generic level in plants, cannot be captured by a single phylogenetic tree. Thus, we used an alternative approach. The plastome is only maternally inherited and should be stronger geographically constrained than the nucleome, but less affected by early (during formation of species/lineages) or late (after formation of species/lineages) reticulation. Therefore, we assume that species with similar plastid signature come from the same area of origin. Similarity in the biparentally-inherited nucleome is taken as indication that two or more taxa are closely related in an evolutionary sense, and have not been isolated for a long time. It has been shown that in densely sampled, sympatric oak species speciation processes directly affect the nucleome, but not the plastome [51-55]. Two closely related species are more likely to hybridize and introgress, which will eventually lead to a homogenization of the nucleome but not necessarily of the plastome. Widespread species with species-diagnostic nuclear signatures can carry distinct plastid signatures (e.g. Quercus coccifera and $Q$. ilex $[54,56])$. Thus, nuclear data will more likely reflect the (current) systematic affinity of an individual or species, whereas plastid data may reflect the provenance of the (mother) population (e.g. $[55,56]$ for oaks, and $[57,58]$ for Nothofagaceae).
The simplest explanation for the geographic distribution of nuclear and plastid lineages (Fig. 4) is that an originally South Asian-Indomalayan sister lineage (orange) of the exclusively Philippine lineage (red), migrated or expanded into the southern Pacific area, possibly in response to the expansion of earlier diverged other Ixora in that region (green and purple members of the African-Asian clade). Alternatively, assuming that the root in the plastid tree may be slightly misinformed (note the central placement of the purple, B-type, haplotypes in the MJ networks in Fig. 5), the divergence between the Pacific (orange) and African-Asian (blue, green) plastids effectively represents a geographic differentiation already between a (continental) South/Southeast Asian (green, purple) and Malesian-Australasian lineage (red and orange; Figs. 4 and 5). In this context, one should note the distinctness of the $\operatorname{trn} \mathrm{T}$-trnL spacers (Fig. 5), the most variable plastid marker included here with an overall divergence hindering alignment across all Ixoroideae. This is combined with lower divergence in the rps 16 and $\operatorname{trn} \mathrm{L}$ introns (and $\operatorname{trn} \mathrm{L}-\operatorname{trn} \mathrm{F}$ spacer), plastid intron (and spacer) regions that can be straightforwardly aligned across all Ixoroideae (Additional file 1 and files provided in the electronic supplementary archive). Taken together, this could be indicative for a widespread common ancestor with a heterogenous plastome that was already starting to diversify due to genetic drift.

Under the primary assumptions (nuclear signal $=$ systematic-phylogenetic affinity; plastid signal = geographic origin), the distinctness of both the nucleome and plastome of the exclusively Philippine lineage (red) suggests that this is the genuine (original) Ixora lineage of the Philippines, or at least a lineage originating and evolving in a different area to the rest of the genus. Thus, the modern mosaic of haplotypes found on the Philippines bears witness of several colonization waves by the African-Asian Ixora (lineage II+IV/B), highlighted by the plastid signatures found in that lineage. Only the least derived haplotypes of this lineage (purple, light green in Fig. 5) - with respect to the trnL intron and downstream trnL-trnF spacer [trnLLF region] and rps16 intron and in comparison to the haplotypes of the Pacific-Philippine lineages - are found on Palawan. More derived types (dark green, violet; Fig. 5) are scattered across the archipelago. These haplotypes can also be found outside of the archipelago (circles in haplotypes networks in Fig. 5), indicating multiple colonizations.

Our study presents an opportunity to make several inferences about the biogeographical patterns and diversification of the Philippine Ixora. In the Philippines, four major colonization routes, or biogeographic umbilici [59] have been identified as entryways to parts of the 
archipelago that have never been connected to a mainland. One colonization route includes the eastern island arc involving Sulu Archipelago-Mindanao-Leyte-SamarLuzon which is most likely the route followed by the species of lineage Ia/A, seeing as their distribution is recorded in these areas. Relatively long isolation from the rest of Ixora and its potential Asian-Pacific siblings, as well as small population size and areas, would explain its marked distinctness (strong genetic drift). Interestingly, lineage Ia/A (orange; Figs. 4 and 5) predominantly occurs in the northern Philippines and comprises species collected from the provinces of Aurora (I. angustilimba), Ilocos Norte (I. bibracteata), Zambales (I. luzoniensis), and Batanes island (Ixora sp. 3). This may reflect the fact that northern Luzon constitutes one of the geologically comparatively old parts of the Philippines that has undergone considerable northwestern movement during the Neogene [5]. Two species from eastern Visayas, I. reynaldoi and I. silagoensis, collected in Samar and Leyte, respectively, as well as the two samples of $I$. bartlingii are also nested within clade Ia/A. Ixora bartlingii is a widespread species found in most islands or provinces but never recorded from the island of Palawan.

The four clades containing Philippine species of lineage(s) II+IV/B are derived from a general Asian group. Thus, our data suggest (at least) four independent colonization events between Southeast Asia and the Philippines for Ixora. This reflects the dispersal mode of the genus, whose fleshy fruits are dispersed by understorey birds with usually limited ranges of action [60].

Palawan is playing a special role in improving our understanding of Southeast Asian biogeography. While the famous Wallace's line [2] separates Wallacea from the Sunda-Region including the Philippines, Huxley's line [61], separates the Philippines (except for Palawan) from the Sunda-Region, thus linking the island of Palawan biogeographically to Borneo. Recent analyses by Van Welzen et al. [50] revealed evidence for partitioning of Malesia into three instead of two regions: the western Sunda Shelf minus Java (Malay Peninsula, Sumatra, Borneo), central Wallacea (Philippines, Sulawesi, Lesser Sunda Islands, Moluccas, Java), and the eastern Sahul Shelf (New Guinea). However, Van Welzen et al. [50] treat Palawan as part of the Philippines, while its plate tectonic history identifies it as part of Sundaland [5]. In our study, we have included five of the eleven Ixora species occurring in Palawan. For lineage Ia/A, our results indeed support the separation of the island from the Philippines along the traditional Huxley's line, because the only widespread species included in this clade, $I$. bartlingii, was never recorded from Palawan. In lineages II/B and IV/B, however, representatives from Palawan are involved in several radiations (Figs. 1 and 5). Nevertheless, the comparison of the corresponding subclades in the nuclear and plastid trees (Fig. 1), and the in-depth analysis of the Philippine plastid haplotypes (Fig. 5) converge to a rather simple hypothetical scenario. The lineage represented by nuclear clade II diversified in Southeast Asia, with a Malesian sublineage (I. iteophylla) reaching Palawan, and (re)colonizing from here the Philippines (subclade with B3 haplotypes; the widespread I. salicifolia is known from Palawan, but could not be included in our study), but also Indonesia (I. otophora). Bottleneck events while jumping into Palawan and the rest of the Philippines would explain the incomplete lineage sorting expressed in the plastid of lineage II/B, with one (non-Philippine) haplotype shared with members of the nuclear clade IV, while the other two are distinct, but of ambiguous phylogenetic affinity within clade B. One hypothesis could be that the founder populations were very small (a few seeds from the same parent population). Once established on Palawan they prevented further migration of their closest relatives. A similar situation may be that observed for Hoya on New Guinea, where the dominant Australasian lineage blocked the migration of two genetically more derived lineages except for a single sublineage each [62]. In contrast, in clade IVa, a clade with relatively underived B-type plastomes, the widespread species I. philippinensis and I. macrophylla are both reported from the island. The fact that the Palawan endemic I. alejandroi groups with the northern accessions of I. philippinensis $(2,5)$, and not with the I. philippinensis accession from Palawan in the southern group, indicates that, at least for this group of species, regular exchange between all Philippine islands, including Palawan, is still taking place. In its sister lineage IVb/B, the widespread species I. cumingiana is present on Palawan as well as on the other islands. Because our study does not include samples of these species from Palawan, their migration routes inside the Philippine archipelago remain to be investigated.

For the species of lineage(s) II+IV/B, our present results support the conclusion of Atkins et al. [11] in Cyrtandra (Gesneriaceae), who found that Palawan has both strong biogeographical ties with the other Philippine islands and, via Borneo, with the remainder of Sundaland. An increased sampling of the species recorded from Indonesia, particularly from Borneo, the most diverse area for the genus [24], will help to disentangle the supposedly multivalent role of Palawan for the biogeographic history of Ixora.

\section{Conclusions}

For Ixora, the Philippines seem to constitute a crossroad where species from two major lineages in Ixora, the Pacific and the African-Asian one, have immigrated and subsequently radiated (Figs. 4 and 5). Our results further 
indicate that no secondary mixing has occurred between the two main lineages, as both nrDNA and cpDNA analyses suggest the same species groups. A more detailed study of lineage(s) II $+\mathrm{IV} / \mathrm{B}$, focusing on Asian material, is needed to understand the complex biogeographical patterns in Ixora inside the Malesian Region and adjacent continental Asia. Future studies should also include more populations, especially of species with wider distributions - be it on several islands or a presumed distribution on mainland Asia - to more finely resolve the phytogeography of the Philippine Ixora species.

\section{Methods}

\section{Taxon sampling}

Fieldwork was conducted in the Philippine islands from 2010 to 2013 in order to collect herbarium, alcohol and DNA material of Philippine Ixora species. We included 72 Ixora accessions (see Additional file 4), representing approximately 60 species of which 19 species are from other Asian countries and 24 species from the Philippines. Three Philippine specimens are potentially new species (pending formal description).

Following Mouly [31] and Alejandro et al. [17], three taxa from the tribes Aleisanthieae (Greeniopsis multiflora Merr. and Aleisanthiopsis distantiflora (Merr.) Tange) and Greeneeae (Greenea corymbosa K.Schum.) were chosen for the purpose of outgroup-rooting. Selection of suitable outgroup taxa was confirmed based on a full gene bank harvest (Additional file 1) for all four gene regions and guide trees optimized under ML (see Additional file 1). All other genera covered by data for all four gene regions are substantially more distant, in phylogenetic terms, from Ixora (see Figs. S1-1 to S1-5 in Additional file 1); and fairly difficult to align with Ixora (particularly in the case of the ITS region).

DNA extraction, amplification, sequencing, and alignment Total DNA was extracted from dried material preserved in silica gel [63] following the protocols of DNeasy Plant Mini Kit (Qiagen, Germany). For the chloroplast regions, PCR mixes were made up to $25 \mu \mathrm{l}$ each and contained $1.0 \mu \mathrm{l} \mathrm{MgCl} 2,2.5 \mu \mathrm{l} 10 \times$ PCR buffer, $2.0 \mu \mathrm{l} \mathrm{dNTP,} 1.0 \mu \mathrm{l}$ of $10 \mu \mathrm{M}$ forward primer, $1.0 \mu \mathrm{l}$ of $10 \mu \mathrm{M}$ reverse primer, $0.35 \mu \mathrm{l}$ Taq DNA polymerase and $1 \mu \mathrm{l}$ of total genomic DNA. Amplification of rps 16 and trnT-F used the following PCR settings: initial melting phase of $2 \mathrm{~min}$ at $95{ }^{\circ} \mathrm{C}$; followed by 35 cycles of $30 \mathrm{~s}$ at $95{ }^{\circ} \mathrm{C}, 1 \mathrm{~min}$ at $50-55{ }^{\circ} \mathrm{C}$, and 2 min at $72{ }^{\circ} \mathrm{C}$; and ended with a final extension phase of $7 \mathrm{~min}$ at $72{ }^{\circ} \mathrm{C}$. The following sequence fragments were amplified: (1) the $3^{\prime}$ part of the 5 ' external transcribed spacer of the nuclear-encoded 35S rDNA (ETS); (2) the complete ITS region comprising the internal transcribed spacers ITS1 and ITS2, and the 5.8S rRNA gene of the $35 \mathrm{~S}$ rDNA; (3) the plastid rps 16 intron; (4) the plastid trnT-trnL intergenic spacer (trnT-L); and (5) the adjacent trnLLF region comprising the $\operatorname{trn} \mathrm{L}$ intron, the downstream ( $5^{\prime}$ or 1 st) $\operatorname{trn} \mathrm{L}$ exon, and trnL-trnF intergenic spacer. For primer pairs see Additional file 5.

PCR mixes for the nuclear regions were the same as for the chloroplast regions, except that $1 \mu \mathrm{l}$ each of dimethylsulfoxide (DMSO) and bovine serum albumin (BSA) were added per $25 \mu \mathrm{l}$. The ETS amplification profile was: initial melting phase of $1 \mathrm{~min}$ at $97{ }^{\circ} \mathrm{C}$; followed by 40 cycles of $10 \mathrm{~s}$ at $97{ }^{\circ} \mathrm{C}, 30 \mathrm{~s}$ at $55^{\circ} \mathrm{C}$, $30 \mathrm{~s}$ at $72{ }^{\circ} \mathrm{C}$; and ended with a final extension phase of $7 \mathrm{~min}$ at $72{ }^{\circ} \mathrm{C}$. The ITS amplification profile was: initial melting phase of $3 \mathrm{~min}$ at $94{ }^{\circ} \mathrm{C}$; followed by 30 cycles of $1 \mathrm{~min}$ at $94{ }^{\circ} \mathrm{C}, 1 \mathrm{~min}$ at $52{ }^{\circ} \mathrm{C}, 1 \mathrm{~min}$ at $72{ }^{\circ} \mathrm{C}$; and ended with a final extension of $7 \mathrm{~min}$ at $72{ }^{\circ} \mathrm{C}$. Primers used for the amplification of nuclear [64-67] and chloroplast [68-71] DNA regions are listed in Additional file 4. PCR amplifications were run on a BIOMETRA thermocycler. All amplification products were cleaned using Qia-Quick PCR purification kit (Qiagen, Germany) and sent to LGC Genomics (Germany) for sequencing.

Forward and reverse sequences were edited and aligned using CodonCode Aligner version 4.0.4 (CodonCode Co., USA) and the consensus was exported in fasta format. The fasta files were aligned using SeaView version 4.0 [72] and the OPAL package [73] inside Mesquite [74] and the resulting alignment was corrected manually, following the recommendations of Kelchner [75]. All variable nucleotide positions were verified against the original electropherograms and final sequences uploaded to the European Nucleotide Archive (ENA).

\section{Phylogenetic analyses}

Separate and combined analyses of the rps16, trnT-F (i.e. $\operatorname{trn} \mathrm{T}$-trnL spacer + trnLLF region), ITS and ETS matrices were performed using the Maximum Likelihood (ML) criterion as implemented in RAxML v. 8.1.20 [76] and Bayesian Markov Chain Monte Carlo (MCMC) inference [77] as implemented in the program MrBayes version 3.1 [78]. For ML, we run partitioned and unpartitioned analyses, treating each gene region as one partition. We used the standard command lines which allow for quick, simultaneous optimization of substitution model, topology and branch support via fast, non-parametric bootstrapping (options $-\mathrm{f} a ;-\mathrm{x} ;-\mathrm{m}$ GTRCAT). The number of necessary bootstrap (BS) replicates were determined by the extended majority rule criterion (-\\# autoMRE [79]). MrBayes analyses used the same partitioning scheme as RAxML and two parallel runs with each one cold and three heated chains (standard set-up), $10^{6}$ generations, 
with every $1000^{\text {th }}$ topology sampled. Posterior probabilities (PP) are based on the final 5000 saved topologies from both runs. Investigation of differential support for alternative relationships can directly reveal significant incongruence between nuclear and plastid genealogies. Phylogenetic resolution at the intrageneric level is typically low, hence, the lack of (high) support should not be taken as indication for incongruence per se. Instead we regard only conflicting relationships as evidence for highly supported incongruence based on the nuclear vs. plastid data $\left(\mathrm{BS}_{\mathrm{ML}}>70\right.$, PP > 0.95; arbitrary thresholds following the common convention in plant phylogenetic literature). Bipartition networks [80], a special form of consensus networks [81] that use either the bootstrap replicate or Bayesian saved tree sample as input [82], visualized the differential support for alternative (competing) relationships (using SplitsTree v. 4.13 [83, 84]; option "count"). 'Rogue' taxa were further pinpointed using tanglegrams generated with Dendroscope $3[85,86]$; the tanglegrams were also used to highlight congruence and incongruence of the nuclear and plastid topologies.

Local, in - detail differentiation patterns used medianjoining (MJ) networks [87], computed with NETWORK v. 4.6 (Fluxus Technology Ltd) using default settings. MJ networks, a derivation of the more general median networks [88], were originally designed to study intraspecific (interpopulation) differentiation [87]. Here, they are used for their capacity to infer (parsimony-based) relationships based on low-divergent data subsets without forcing each sequence variant to the tip of a single tree (e.g. $[89,90])$. The original matrices were first filtered for parsimony informative sites (to eliminate "satellite" sequence variants or singletons differing only by stochastic mutations from others) using PAUP* v. $4 \mathrm{~b} 10$ [91]; occasional gaps (no prominent length polymorphism present) were treated as 5th base for the inference (gaps involving more than a single parsimonyinformative site were treated as one mutational event for the final graphical representation). For MJ networks, the trnT-trnL and trnLLF region were treated separately to account for their different diversity.

\section{Additional files}

Additional file 1: Details relating to the curation and analysis of the data harvested from gene banks to confirm selection of best-suited outgroups (PDF $1128 \mathrm{~kb})$

Additional file 2: Additional Figures $\mathbf{A}$. Tanglegram showing maximum likelihood trees based on the nuclear (left) and the plastid (right) datasets including all sampled cultivated species (in red font). Branch numbers indicate bootstrap support values and posterior probabilities for selected branches. Clade designation as in main-text Fig. 1. B. Posterior probability (PP) networks based on the nuclear dataset with cultivars removed. Edge lengths are proportional to the PP of the corresponding taxon bipartition (branch in a tree). Clade designation and colouring as in main-text Fig. 2. C. Posterior probability (PP) networks based on the plastid dataset with cultivars removed. Edge lengths are proportional to the PP of the corresponding taxon bipartition (branch in a tree). Clade designation and colouring as in main-text Fig. 2 (PDF 688 kb)

Additional file 3: Overview and detailed list of ribo-/haplotypes resulting from the tree inferences and median-joining analyses (XLSX $103 \mathrm{~kb}$ )

Additional file 4: List of included specimens, with GenBank accession numbers (PDF $25 \mathrm{~kb}$ )

Additional file 5: List of used primers for amplification of nuclear and plastid target gene regions (PDF $15 \mathrm{~kb}$ )

\section{Abbreviations}

BS: Bootstrap; BSA: Bovine Serum Albumin; cpDNA: chloroplast DNA; DAP: Distinct alignment pattern; DMSO: Dimethylsulfoxide;

DNA: Deoxyribonucleic acid; ENA: European nucleotide archive; ETS: External transcribed spacer; ITS: Internal transcribed spacer; MCMC: Bayesian Markov Chain Monte Carlo; MJ: Median joining; ML: Maximum likelihood; nrDNA: Nuclear DNA; PAUP: Phylogenetic analysis using parsimony *and other methods; PCR: Polymerase chain reaction; PIC: Parsimony informative character; PP: Posterior probability; RAxML: Randomized axelerated maximum likelihood; rps16: Ribosomal protein S16; trn: tRNA gene

\section{Acknowledgements}

The first author thanks Danilo Tandang and Arvin Diesmos of the Philippine National Museum as well as the Thomasian Angiosperm Phylogeny and Barcoding group for help and assistance during field collections, and Angelika Täuber (Univ. of Bayreuth) for guidance during the molecular work. The present work is part of the doctoral dissertation of C.I. Banag, for which financial assistance was obtained from Philippine Commission on Higher Education (CHED), Department of Science and Technology (DOST), NAGAO Natural Environment Foundation (NEF), DAAD STIBET Grants for Doctoral Studies, and the Katholischer Akademischer Ausländer-Dienst (KAAD). GWG acknowledges funding by the Austrian Science Fund, project number M1751-B16, and the Public Employment Service (AMS) Austria. This publication was funded by the German Research Foundation (DFG) and the University of Bayreuth in the funding programme Open Access Publishing. The authors thank Mark P. Simmons, Colorado State University, and particularly an anonymous reviewer for their comments on an earlier draft of the paper. We are grateful to Thomas Denk, Naturhistoriska riksmuseet, Stockholm, for a constructive review of the revised manuscript and Maxine Smit, Nelson Mandela Metropolitan University, for language editing.

\section{Availability of data and materials}

The datasets supporting the conclusions of this article are available in TreeBase (http://purl.org/phylo/treebase/phylows/study/TB2:S20219). An electronic supplementary data archive (ESA) containing all original data files and results, including the NCBI GenBank harvest and all employed matrices in NEXUS format, is available for anonymous download at www.palaeogrimm.org/data/Bng17_ESF.zip (please refer to the accompanying index document, GuideToFiles.txt, for a detailed description). Lists of voucher specimens, ENA (European Nucleotide Archive) accession numbers, and primers used are included in this article as Additional files.

\section{Authors' contributions}

CIB, GJDA and SLS designed the study, CIB obtained and analysed the plant material. AM provided material and unpublished sequences from specimens outside the Philippines. BB advised CIB on material selection and commented on the manuscript. UM assisted in data acquisition and documentation of studied material. CIB, GWG and SLS conceived and performed the phylogenetic analyses. UM and GWG provided the artwork, and GWG and SLS compiled the supplementary material. All authors read and approved the final manuscript.

\section{Competing interests}

The authors declare they have no competing interests.

Ethics approval and consent to participate Not applicable. 


\section{Publisher's Note}

Springer Nature remains neutral with regard to jurisdictional claims in published maps and institutional affiliations.

\section{Author details}

'Department of Biological Sciences, College of Science, University of Santo Tomas, España Boulevard, 1015 Manila, Philippines. ${ }^{2}$ Research Center for the Natural and Applied Sciences, University of Santo Tomas, España Boulevard, 1015 Manila, Philippines. ${ }^{3}$ Bergius Botanic Garden, Stockholm University, 106 91 Stockholm, Sweden. ${ }^{4}$ Department of Plant Systematics, University of Bayreuth, Universitätstraße 30, 95440 Bayreuth, Germany. ${ }^{5}$ UMR CNRS 6249 Chrono-environnement, Université Bourgogne - Franche-Comté, 16 Route de Gray, 25030 Besançon cedex, France. ${ }^{6}$ Orléans, France.

Received: 1 December 2016 Accepted: 18 May 2017 Published online: 07 June 2017

\section{References}

1. Wallace AR. On the zoological geography of the Malay Archipelago. J Proc Linn Soc. 1860:4:172-84.

2. Wallace AR. On the physical geography of the Malay Archipelago. J R Geogr Soc. 1863:33:217-34

3. Wallace AR. The geographical distribution of animals, vol. 1 and 2. London: Macmillan; 1876.

4. Myers N, Mittermeier RA, Mittermeier CG, GABd F, Kent J. Biodiversity hotspots for conservation priorities. Nature. 2000;403:853-8.

5. Hall R. Cenozoic geological and plate tectonic evolution of SE Asia and the SW Pacific: computer-based reconstructions, model and animations. J Asian Earth Sci. 2002;20:353-431.

6. Brown RM, Siler CD, Oliveros CH, Esselstyn JA, Diesmos AC, Hosner PA, et al. Evolutionary processes of diversification in a model island archipelago. Ann Rev Ecol Evol Syst. 2013;44:411-35.

7. Siler CD, Diesmos AC, Alcala AC, Brown RM. Phylogeny of Philippine slender skinks (Scincidae: Brachymeles) reveals underestimated species diversity, complex biogeographical relationships, and cryptic patterns of lineage diversification. Mol Phylogenet Evol. 2011;59:53-65.

8. Esselstyn JA, Maher SP, Brown RM. Species interactions during diversification and community assembly in an island radiation of shrews. PLoS One. 2011; $6: e 21885$.

9. Brown RM, Diesmos AC. Philippines, Biology. In: Gillespie RG, Clague DA, editors. Encyclopedia of Islands. Berkeley: University of California Press; 2009. p. 723-32.

10. Heaney LR. Is a new paradigm emerging for oceanic island biogeography? J Biogeogr. 2007;34:753-7.

11. Atkins H, Preston J, Cronk QCB. A molecular test of Huxley's line: Cyrtandra (Gesneriaceae) in Borneo and the Philippines. Biol J Linn Soc. 2001;72:143-59.

12. Brown GK, Craven LA, Udovicic F, Ladiges PY. Phylogenetic relationships of Rhododendron section Vireya (Ericaceae) inferred from the ITS nrDNA region. Aust Syst Bot. 2006;19:329-42.

13. Hughes M, Rubite RR, Blanc P, Chung K, Peng C. The Miocene to Pleistocene colonization of the Philippine Archipelago by Begonia sect. Baryandra (Begoniaceae). Am J Bot. 2015;102:695-706.

14. Thomas DC, Hughes M, Phutthai T, Ardi WH, Rajbhandary S, Rubite R, et al. West to east dispersal and subsequent rapid diversification of the megadiverse genus Begonia (Begoniaceae) in the Malesian archipelago. J Biogeogr. 2012;39:98-113.

15. Grudinski M, Wanntorp L, Pannell CM, Muellner-Riehl AN. West to east dispersal in a widespread animal-dispersed woody angiosperm genus (Aglaia, Meliaceae) across the Indo-Australian Archipelago. J Biogeogr. 2014:41:1149-59.

16. Davis AP, Govaerts R, Bridson DM, Ruhsam M, Moat J. A global assessment of distribution, diversity, endemism, and taxonomic effort in the Rubiaceae. Ann Missouri Bot Gard. 2009;96:68-78.

17. Alejandro GJD, Meve U, Uy M, Mouly A, Thiv M, Liede-Schumann S. Molecular support of the classification of Greeniopsis Merr. in Aleisanthieae (Rubiaceae), with a revision of the genus. Taxon. 2010;59:1547-64.

18. Obico JJA, GJD A. Molecular phylogeny of the Philippine endemic genus Antherostele Bremek. (Rubiaceae) inferred from ITS data (nrDNA) and its conservation status. Am J Plant Sci. 2012:3:4

19. Alejandro GJD, Meve U, Mouly A, Thiv M, Liede-Schumann S. Molecular phylogeny and taxonomic revision of the Philippine endemic Villaria Rolfe (Rubiaceae). Plant Syst Evol. 2011;296:1-20.
20. Andreasen K, Bremer B. Combined phylogenetic analysis in the RubiaceaeIxoroideae: morphology, nuclear and chloroplast DNA data. Am J Bot. 2000; $87: 1731-48$

21. De Block P. The African species of Ixora (Rubiaceae - Pavetteae). Opera Bot Belg. 1998;9:1-217.

22. Sivadasan $M$, Mohanan N. Ixora agasthyamalayaría, a new species of Rubiaceae from India. Bot Bull Acad Sin. 1991;32:313-6.

23. Chamchumroon V. A checklist of the genus Ixora L. (Rubiaceae) in Thailand. Thai Forest Bulletin (Botany). 2014;34:4-24.

24. Bremekamp CEB. The Malaysian species of the genus Ixora (Rubiaceae). Bull Jard Bot Buitenzorg Ser 3. 1937;14:197-367.

25. De Block P. Eight new species of Ixora (Ixoreae - Rubiaceae) from Madagascar. Plant Ecol Evol. 2014;147:237-55.

26. Lorence DH, Wagner WL, Mouly A, Florence J. Revision of Ixora (Rubiaceae) in the Marquesas Islands (French Polynesia). Bot J Linn Soc. 2007:155:581-97.

27. Reynolds ST, Forster PI. A taxonomic revision of Ixora L. (Rubiaceae: Ixoroideae) in Australia. Austrobaileya. 2006;7:253-78.

28. Mouly A. Systématique de la tribu des Ixoreae A. Gray (Rubiaceae): phylogénie, biogéographie et taxinomie. Acta Bot Gall. 2008;155:457-64.

29. Andreasen K, Bremer B. Phylogeny of the subfamily Ixoroideae (Rubiaceae). Opera Bot Belg. 1996;7:119-38.

30. Mouly A, Razafimandimbison S, Florence J, Jérémie J, Bremer B. Paraphyly of Ixora and new tribal delimitation of Ixoreae (Rubiaceae): inference from combined chloroplast ( $r p s 16, r b c L$, and trnT-F) sequence data. Ann Missouri Bot Gard. 2009;96:146-60.

31. Mouly A, Razafimandimbison S, Khodabandeh A, Bremer B. Phylogeny and classification of the species-rich pantropical showy genus /xora (Rubiaceae-|xoreae) with indications of geographical monophyletic units and hybrids. Am J Bot. 2009:96:686-706.

32. Tosh J, Dessein S, Buerki S, Groeninckx I, Mouly A, Bremer B, et al. Evolutionary history of the Afro-Madagascan Ixora species (Rubiaceae): species diversification and distribution of key morphological traits inferred from dated molecular phylogenetic trees. Ann Bot. 2013;112: 1723-42.

33. Cohen KM, Finney SC, Gibbard PL, Fan J-X. The ICS International Chronostratigraphic Chart. Episodes. 2013;36:199-204.

34. Alejandro GJD. The current status of the Philippine Rubiaceae. Philipp J Syst Biol. 2007;1:47-60.

35. Banag Cl. Systematics of the Philippine endemic Ixora L. (Rubiaceae, Ixoreae). Ph.D. Bayreuth: University of Bayreuth; 2014.

36. Merrill ED. An enumeration of Philippine Flowering Plants, vol. 3. Bureau of Printing: Manila; 1923.

37. Alejandro GJD, Liede S. The Philippine Rubiaceae genera. Updated synopsis in INTKEY databases of the DELTA system. Blumea. 2003:48: 261-77.

38. Robbrecht E, Manen JF. The major evolutionary lineages of the coffee family (Rubiaceae, angiosperms). Combined analysis (nDNA and cpDNA) to infer the position of Coptosapelta and Luculia, and supertree construction based on $r b c L$, rps 16, trnL-trnF and atpB-rbcL data. A new classification in two subfamilies, Cinchonoideae and Rubioideae. Syst Geogr Plants. 2006:76:85-146.

39. Bremer B, Eriksson T. Time tree of Rubiaceae: phylogeny and dating the family, subfamilies, and tribes. Int J Plant Sci. 2009:170:766-93.

40. Wendel JF, Doyle JJ. Phylogenetic incongruence: window into genome history and molecular evolution. In: Soltis PS, Soltis DE, Doyle JJ, editors. Molecular systematics of plants, vol. 2. Boston: Kluwer; 1998. p. 265-96.

41. Sun M, Soltis DE, Soltis PS, Zhu X, Burleigh JG, Chen ZD. Deep phylogenetic incongruence in the angiosperm clade Rosidae. Molec Phy Evol. 2015;83:156-66.

42. Elmer ADE. New and noteworthy Rubiaceae. Leafl Philipp Bot. 1906;1:8-9.

43. Merrill ED. New or noteworthy Philippine Plants, XVI. Philipp J Sci C (Bot). 1921:17:320-1

44. Banag Cl, Manalastas NMB, Alejandro GJD: Synonymy of Philippine Ixora (Ixoreae, Rubiaceace) and Ixora silagoensis sp. nov. Nord J Botany. 2014; 32:761-764

45. Banag $\mathrm{Cl}$, Tandang D, Meve U, Liede-Schumann S. Two new species of Ixora (Ixoroideae, Rubiaceae) endemic to the Philippines. Phytotaxa. 2015;202:155-60.

46. Mouly A, Deroin T, Verhaegen D, Munzinger J. The emblematic "Captaincookia" in New Caledonia (Rubiaceae), a divergent Ixora species showing adaptative variability from humid to sclerophyll forests. Plant Ecol Evol. 2016;149:112-22. 
47. Linder $C R$, Rieseberg $L$. Reconstructing patterns of reticulate evolution in plants. Am J Bot. 2004;91:1700-8.

48. Jones AW, Kennedy RS. Evolution in a tropical archipelago: comparative phylogeography of Philippine fauna and flora reveals complex patterns of colonization and diversification. Biol J Linn Soc. 2008;95:620-39.

49. Turner IM. Robinson a century on: the nomenclatural relevance of Roxburgh's Hortus Bengalensis. Taxon. 2013;62:152-72.

50. Van Welzen PC, Parnell JAN, Ferry Slik JW. Wallace's Line and plant distributions: two or three phytogeographical areas and where to group Java? Biol J Linn Soc. 2011;103:531-45.

51. Neophytou C, Aravanopoulos FA, Fink S, Dounavi A. Interfertile oaks in an island environment: II. Limited hybridization Quercus alnifolia Poech and Q. coccifera L. in a mixed stand. Eur J For Res. 2011;130:623-35.

52. Neophytou C, Aravanopoulos FA, Fink S, Dounavi A. Detecting interspecific and geographic differentiation pattern in two interfertile oak species (Quercus petraea (Matt.) Liebl. and Quercus robur L.). For Ecol Manag. 2010; 259:2026-35.

53. Neophytou C, Dounavi A, Fink S, Aravanopoulos FA. Interfertile oaks in an island environment: I. High nuclear genetic differentiation and high degree of chloroplast DNA sharing between Q. alnifolia and Q. coccifera in Cyprus. A multipopulation study. Eur J For Res. 2010;130:543-55.

54. Denk T, Grimm GW. The oaks of western Eurasia: traditional classifications and evidence from two nuclear markers. Taxon. 2010;59:351-66.

55. Simeone MC, Grimm GW, Papini A, Vessella F, Cardoni S, Tordoni E, et al. Plastome data reveal multiple geographic origins of Quercus Group Ilex. PeerJ. 2016;4:e1897.

56. Vitelli M, Vessella F, Cardoni S, Pollegioni P, Denk T, Grimm GW, et al. Phylogeographic structuring of plastome diversity in Mediterranean oaks (Quercus Group Ilex, Fagaceae). Tree Genet Genomes. 2017;13:3. [e-Pub]

57. Acosta MC, Premoli AC. Evidence of chloroplast capture in South American Nothofagus (subgenus Nothofagus, Nothofagaceae). Mol Phylogenet Evol. 2010;54:235-42.

58. Premoli AC, Mathiasen P, Acosta MC, Ramos VA. Phylogeographically concordant chloroplast DNA divergence in sympatric Nothofagus s.s. How deep can it be? New Phytol. 2012;193:261-75.

59. Diamond JM, Gilpin ME. Biogeographic umbilici and the origin of Philippines avifauna. Oikos. 1983;41:301-21.

60. Banag Cl, Thrippleton T, Alejandro GJD, Reineking B, Liede-Schumann S. Bioclimatic niches of selected endemic Ixora species on the Philippines: predicting habitat suitability due to climate change. Plant Ecol. 2015;216: $1325-40$.

61. Huxley TH. On the classification and distribution of the Alectoromorphae and Heteromorphae. Proc Zool Soc London. 1868;1868:294-319.

62. Wanntorp L, Grudinski M, Forster PI, Muellner-Riehl AN, Grimm GW. Wax plants (Hoya, Apocynaceae) evolution: epiphytism drives successful radiation. Taxon. 2014;63:89-102.

63. Chase MW, Hills HH. Silica gel: An ideal material for field preservation of leaf samples for DNA studies. Taxon. 1991;40:215-20.

64. Baldwin BG, Markos S. Phylogenetic utility of the external transcribed spacer (ETS) of 18S-26S rDNA: congruence of ETS and ITS trees of Calycadenia (Compositae). Mol Phylogenet Evol. 1998;10:449-63.

65. Razafimandimbison SG, Lantz H, Mouly A, Bremer B. Evolutionary trends, major lineages, and new generic limits in the dioecious group of the tribe Vanguerieae (Rubiaceae): Insights into the evolution of functional dioecy. Ann Missouri Bot Gard. 2009:96:161-81.

66. White TJ, Bruns T, Lee S, Taylor J. Amplification and direct sequencing of fungal ribosomal RNA genes for phylogenetics. In: Innis MA, Gelfand DH, Sninsky JJ, White TJ, editors. PCR protocols: a guide to methods and applications. San Diego: Academic Press; 1990. p. 315-22

67. Urbatsch LE, Baldwin BG, Donoghue MJ. Phylogeny of the coneflowers and relatives (Heliantheae: Asteraceae) based on nuclear rDNA internal transcribed spacer (ITS) sequences and chloroplast DNA restriction site data. Syst Bot. 2000;25:539-65.

68. Oxelman B, Liden M, Berglund D. Chloroplast rps16 intron phylogeny of the tribe Sileneae (Caryophyllaceae). Plant Syst Evol. 1997;206:393-410.

69. Lantz H, Bremer B. Phylogeny inferred from morphology and DNA data: characterizing well-supported groups in Vanguerieae (Rubiaceae). Bot J Linn Soc. 2004;146:257-83.

70. Bremer B, Bremer K, Heidari N, Erixon P, Olmstead RG, Anderberg AA, et al. Phylogenetics of asterids based on 3 coding and 3 non-coding chloroplast
DNA markers and the utility of non-coding DNA at higher taxonomic levels. Mol Phylogenet Evol. 2002;24:274-301.

71. Taberlet PL, Gielly L, Patou G, Bouvet J. Universal primers for amplification of three noncoding regions of chloroplast DNA. Plant Mol Biol. 1991;17:1105-9.

72. Gouy M, Guindon S, Gascuel O. SeaView version 4 : a multiplatform graphical user interface for sequence alignment and phylogenetic tree building. Mol Biol Evol. 2010;27:221-4

73. Wheeler TJ, Kececioglu JD. Multiple alignments by aligning alignments. Bioinformatics. 2007;23:1559-68.

74. Maddison WP, Maddison DR: Mesquite: a modular system for evolutionary analysis. Version 2.75 http://mesquiteproject.org. 2011.

75. Kelchner SA. The Evolution of non-coding chloroplast DNA and its application in plant systematics. Ann Missouri Bot Gard. 2000;87:482-98.

76. Stamatakis A. RAxML version 8: a tool for phylogenetic analysis and postanalysis of large phylogenies. Bioinformatics. 2014;30:1312-3.

77. Yang Z, Rannala B. Bayesian phylogenetic inference using DNA sequences: a Markov chain Monte Carlo method. Mol Biol Evol. 1997;14:717-24.

78. Ronquist F, Huelsenbeck JP. MrBayes 3: Bayesian phylogenetic inference under mixed models. Bioinformatics. 2003;19:1572-4.

79. Pattengale ND, Masoud A, Bininda-Emonds ORP, Moret BME, Stamatakis A. How many bootstrap replicates are necessary? In: Batzoglou S, editor. RECOMB 2009, vol. 5541. Berlin: Springer-Verlag; 2009. p. 184-200.

80. Grimm GW, Renner SS, Stamatakis A, Hemleben V. A nuclear ribosomal DNA phylogeny of Acer inferred with maximum likelihood, splits graphs, and motif analyses of 606 sequences. Evol Bioinforma. 2006;2:279-94.

81. Holland B, Moulton V. Consensus networks: a method for visualising incompatibilities in collections of trees. In: Benson G, Page R, editors. Algorithms in Bioinformatics: Third International Workshop, WABI, Budapest, Hungary Proceedings, vol. 2812. Berlin: Stuttgart: Springer Verlag; 2003. p. 165-76.

82. Schliep K, Potts AJ, Morrison DA, Grimm GW. Intertwining phylogenetic trees and networks. Methods Evol Evol. 2017. doi:10.1111/2041-210X.12760.

83. Huson DH. SplitsTree: analyzing and visualizing evolutionary data. Bioinformatics. 1998;14(1):68-73.

84. Huson DH, Bryant D. Application of phylogenetic networks in evolutionary studies. Mol Biol Evol. 2006;23(2):254-67.

85. Huson DH, Dezulian T, Rausch C, Richter D, Rupp R. Dendroscope: visualization of large trees. Tübingen: University of Tübingen, ZBIT, Department Algorithms in Bioinformatics; 2007.

86. Huson DH, Scornavacca C. Dendroscope 3: an interactive tool for rooted phylogenetic trees and networks. Syst Biol. 2012;61:1061-7.

87. Bandelt $\mathrm{H}-\mathrm{J}$, Forster $\mathrm{P}$, Röhl A. Median-joining networks for inferring intraspecific phylogenies. Mol Biol Evol. 1999;16:37-48.

88. Bandelt H-J, Forster P, Sykes BC, Richards MB. Mitochondrial portraits of human populations using median networks. Genetics. 1995;141:743-53.

89. Grimm GW, Denk T. The reticulate origin of modern plane trees (Platanus, Platanaceae) - a nuclear marker puzzle. Taxon. 2010;59:134-47.

90. Christe C, Kozlowski G, Frey D, Bétrisey S, Maharramova E, Garfi G, et al. Footprints of past intensive diversification and structuring in the genus Zelkova (Ulmaceae) in south-western Eurasia. J Biogeogr. 2014;41:1081-93.

91. Swofford DL: PAUP*: Phylogenetic Analysis Using Parsimony (and Other Methods). Sunderland: Sinauer Associates; 2002.

92. Pelser PB, Barcelona JF, Nickrent DL. Co's Digital Flora of the Philippines. 2011 onwards. www.philippineplants.org.

\section{Submit your next manuscript to BioMed Central and we will help you at every step:}

- We accept pre-submission inquiries

- Our selector tool helps you to find the most relevant journal

- We provide round the clock customer support

- Convenient online submission

- Thorough peer review

- Inclusion in PubMed and all major indexing services

- Maximum visibility for your research

Submit your manuscript at www.biomedcentral.com/submit 